\title{
Determination of crack growth direction for multiple offset edge cracks of a finite plate
}

\author{
P.K. Arora ${ }^{a^{*}, \text { S C. Srivastava }}{ }^{\mathrm{b}}$ and Harish Kumar ${ }^{\mathrm{c}}$
}

${ }^{a}$ Galgotias College of Engineering and Technology, Greater Noida, India

${ }^{b}$ Birla Institute of Technology Mersa, Ranchi, India

${ }^{c}$ CSIR - National Physical Laboratory, New Delhi, India

\begin{tabular}{l}
\hline A R T I C L EI N F O \\
\hline Article history: \\
Received 6 January, 2017 \\
Accepted 20 May 2017 \\
Available online \\
21 May 2017 \\
\hline Keywords: \\
Crack initiation angle \\
Coalescence \\
Offset-crack \\
Self-similar crack growth \\
Non self-similar crack growth
\end{tabular}

\section{A B S T R A C T}

\begin{abstract}
An approximated crack growth direction and coalescence of the multiple cracks were obtained for an aluminum alloy plate by the finite element approach (FEA). Self-similar as well as nonself-similar crack growths were observed based on relative position of multiple cracks. The FE predictions of crack growth direction are validated with an experimental results and good agreement is established. Typical numerical results are presented to examine the effect of changing the crack tip distance (S), crack offset distance $(\mathrm{H})$ on crack growth direction and coalescence of a finite aluminum alloy aluminum plate. Based on the analysis and experimental results, a new mathematical models for self-similar and non-self similar crack growth are introduced.
\end{abstract}

\section{Nomenclature}

$\begin{array}{llll}\mathrm{a} & \text { crack length } & \mathrm{E} & \text { modulus of elasticity } \\ \mathrm{w} & \text { width of Plate } & \mathrm{K}_{\mathrm{I}} \& \mathrm{~K}_{\mathrm{II}} & \text { stress intensity factor for Mode-I \& } \\ \mathrm{h} & \text { height of plate } & \text { Mode-II } & \\ \theta & \text { crack initiation angle } & \mathrm{E} & \text { modulus of elasticity } \\ \mathrm{t} & \text { thickness of plate } & \sigma_{\mathrm{y}} & \text { yield stress } \\ \alpha & \text { crack inclination angle } & \sigma_{\mathrm{u}} & \text { ultimate stress } \\ \mathrm{F} & \text { applied load } & \delta & \text { elongation } \\ \mu & \text { Poisson's ratio } & \varepsilon_{\mathrm{f}} & \text { failure strain } \\ \mathrm{S} & \text { crack tip distance } & \varepsilon_{\mathrm{ep}} & \text { effective plastic strain } \\ \mathrm{H} & \text { crack offset distance } & & \end{array}$

\footnotetext{
* Corresponding author.

E-mail addresses: pawanar@rediffmail.com (P.K. Arora) 


\section{Introduction}

Aluminum (Al) alloy structures have found extensive applications in aerospace, defense, transport industry, utensil industries, etc. due to unique properties such as high strength to weight ratio, fatigue strength, corrosion resistance, and, ductility with high structural efficiency, durability, and workability. In comparison with fiber reinforced composite and other alloys, Al alloy offers more cost saving with greater performance increments due to low density. However, the use of Al alloy has been inhibited in their potential applications due to limited ductility, inferior low cycle fatigue resistance, and low fracture toughness.

The crack interaction involves two typical features of crack growth behaviors: crack coalescence and stagnation. The coalescence of approaching cracks, is frequently observed in crack growth processes. On the other hand, cracks may stop growing due to the stress shielding effect caused by the presence of other cracks in the neighborhood. The interaction between the multiple cracks can be studied either analytically or experimentally. Analytical approach involves numerical evaluations based on empirical relationships between the crack growth rate and the stress intensity factors (SIFs). The relative position of interacting crack changes according to their growth. Therefore, it is necessary to examine not only the relationship between the SIFs value and the relative position, but also the change in this relationship with the crack growth process needs to study.

Multiple cracks of an aircraft structure and rivet holes can be initiated because of cyclic load and engine vibration during flight. The presence of crack may reduce strength and stability of an aircraft and its components considerably. The proposed concept of crack growth is useful while assessing damage tolerance behavior and component life of an aircraft. It can further be used during implementation of repair schemes for the cracks observed during service phase of aircraft structural components.

The interaction between multiple cracks has a major influence on crack growth behaviors. This influences particularly significant in stress corrosion cracking (Kamaya, \& Totsuka, 2002), welding (Cisilino \& Aliabadi, 1997; Wessel et al., 2001), multiple site damage in aging aircraft (Zhao et al. 2012) and cold expended fasteners holes in aircraft components (Lacarac et al., 2004). The growth direction is computed either by using strain energy density (SED) criterion or maximum tangential stress (MTS) criterion (Sih, 1974; Sih \& Barthelemy, 1980; Yan, 2006, Aliha et al., 2016a,b; Akbardoost et al., 2014; Mirsayar et al., 2016, Ayatollahi et al., 2006,2011; Aliha \& Ayatollahi 2008) as no such standard relations is available to compute the crack growth direction based on the relative crack positions. Strain energy release rate based on virtual crack closure technique is developed by introducing an interface element to solve crack growth problem (Xie et al., 2006; Liu et al., 2011). Experimental and finite element studies on mode-I and mode -II crack growth shows good agreement (Maiti \& Mahanty, 1990; Lee \& Jeon, 2011). Crack propagation is perhaps the most thoroughly study need to carry out in the area of fracture mechanics. However, the theories that have so far been developed are not fully capable of predicting the crack growth process that occurs in service. The problem can be further complicated by multiple cracks in the structure. The magnitude of the interaction is dependent on various factors, such as, relative size, relative locations, crack shape, and number of cracks (Kamaya, 2008).

The SIFs are very important parameters for fracture mechanics analyses. An essential part of the solution of fracture problem is the evaluation of the SIFs. In most of the studies under multiple crack systems, SIFs are either evaluated from the superposing and compounding the stress intensity factors solution (Bombardier \& Liao, 2011), finite element model and force method (De Morais, 2007) and energy release-rate method (Wang \& Zhang, 1999). The effects of uncertainties in material properties, crack length, and load on SIFs were explored using Taylor stochastic finite element method (SFEM) (Xiaofeng et al., 2009) and Gaussian Monte Carlo method (Romlay et al., 2010; Cadini et al., 2009). The available literature is unable to detect the effect of relative crack positions on multiple crack 
configurations. The present study focuses on the influence of crack position defined by crack offset distance, and crack tip distance on growth direction.

\section{Material and specimen}

The study of crack growth direction under tensile loading was conducted considering multiple offset and inclined cracks. Crack growth direction is determined considering multiple edge cracks (Fig.1a), multiple central cracks (Fig.1b), and multiple inclined central crack (Fig. 1c). An Al alloy plate of $60 \times 200 \times 1 \mathrm{~mm}^{3}$ was used as a specimen for all the cases.

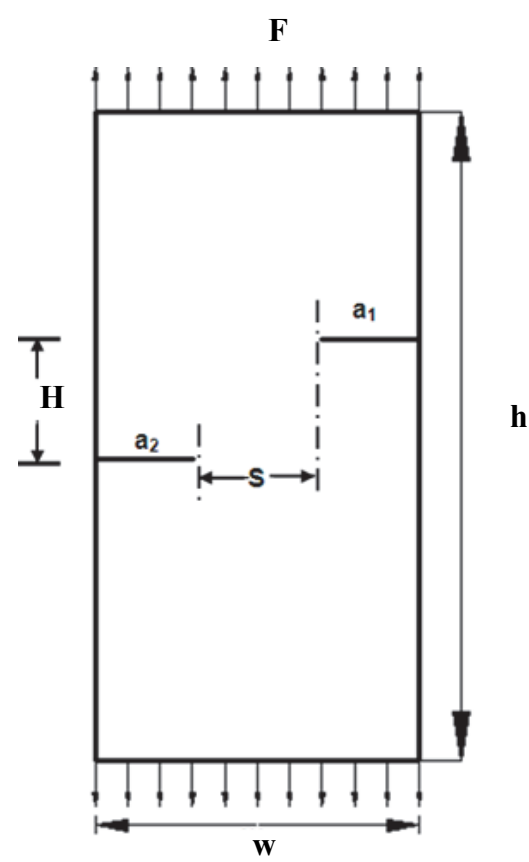

(a) Offset edge crack

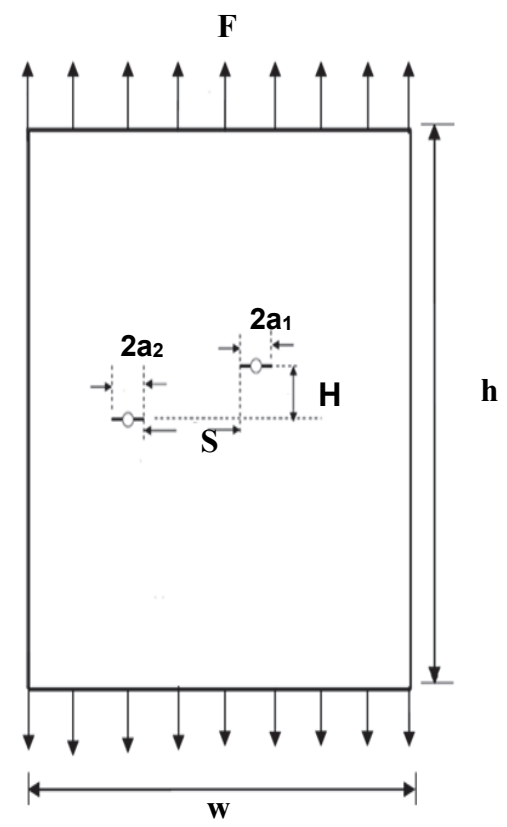

(b) Offset central crack

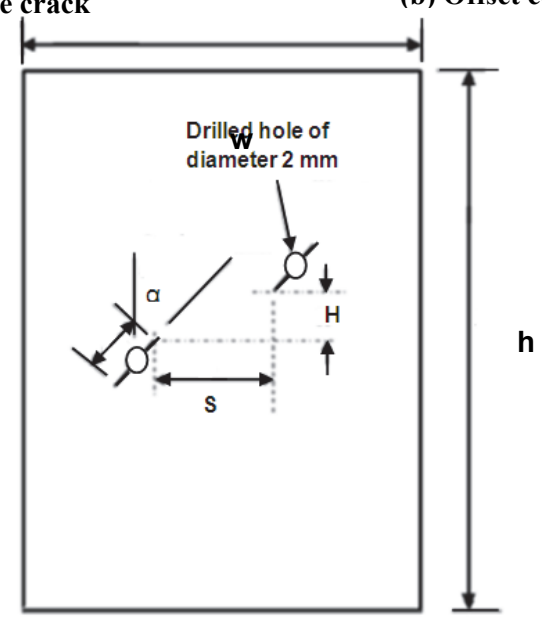

(c) central inclined crack

Fig. 1. Specimen geometry along with multiple cracks

Two holes of diameter $2 \mathrm{~mm}$ were created by drilling at the center of cracks and edge cracks were generated on specimen by the water jet machine (WJM). All inclined cracks were introduced at an angle $60^{\circ}$ relative to the vertical axis. Mechanical properties of an Al alloy used in the computation as shown in Table 1.

Table 1. Mechanical Property of tested Al alloy

\begin{tabular}{lrccccc}
\hline Specimen configuration & $\mathrm{E}(\mathrm{GPa})$ & $\mu$ & $\sigma_{\mathrm{y}}(\mathrm{MPa})$ & $\sigma_{\mathrm{u}}(\mathrm{MPa})$ & $\% \delta$ & $\varepsilon_{\mathrm{f}}$ \\
\hline 7072-Aluminum alloy & 70 & 0.3 & 99 & 106 & $14-15$ & $0.25-0.30$ \\
\hline
\end{tabular}




\section{Methodology}

Fig. 2 presents the systematic overview of integrated approach used in present study for the multiple crack configurations, which deals with simulation of crack propogation by testing and FE approach. Testing of the specimen is carried out using universal testing machine (UTM), whereas FE analysis is carried out using explicit code of LS Dyna software. Effect of changing the crack tip distance and crack offset distance on crack growth direction is studied using maximum nominal strain criterion discuseed in susequent section 3.1.2. Crack growth angle is measured on fratured specimen during experiment and FE simulation.Details of the experiment and FE anaysis are presented in susequent section 3.4.

\subsection{Damage initiation}

Present study discusses the crack growth and coalesence of multiple cracks by the cohesive damage approach (Li \& Chandra 2003). Damage initiation refers to the beginning of degradation of the response of a material point. The process of degradation starts when the stresses and/or strains satisfy certain damage initiation criteria. Fig. 3 shows a typical traction-separation response with a failure mechanism. Several damage initiation criteria are available and are discussed below. A value of 1 or higher indicates that the initiation criterion has been met.

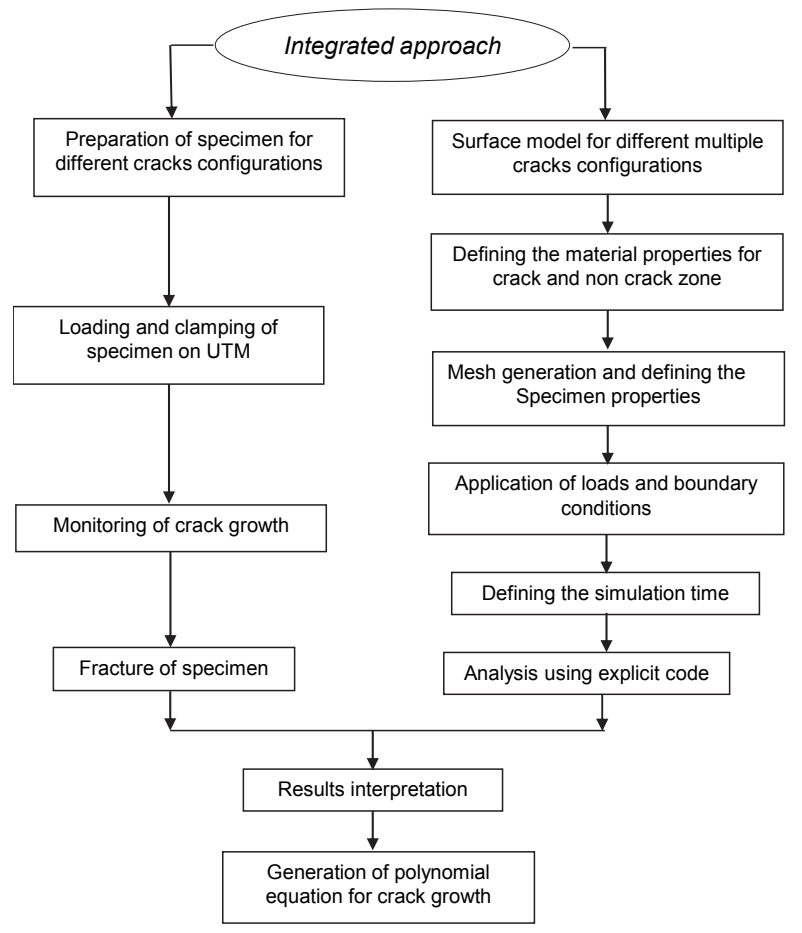

Fig. 2. Systematic overview of present study

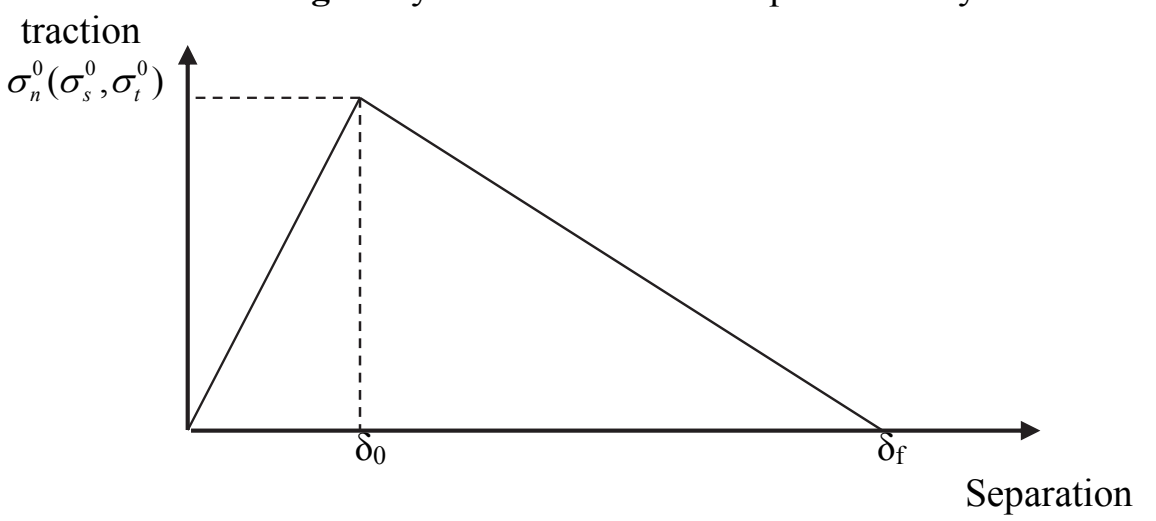

Fig. 3. Typical traction-separation response 


\subsubsection{Maximum Nominal Stress Criterion}

Damage is assumed to initiate when the maximum nominal stress ratio reaches a value of one. This criterion can be represented as

$$
\max \left\{\frac{\sigma_{n}}{\sigma_{n}^{o}}, \frac{\sigma_{s}}{\sigma_{s}^{o}}, \frac{\sigma_{t}}{\sigma_{t}^{o}}\right\}=1
$$

\subsubsection{Maximum Nominal Strain Criterion}

Damage is assumed to initiate when the maximum nominal strain ratio reaches a value of one. This criterion can be represented as (Erdogan \& Sih, 193)

$$
\max \left\{\frac{\varepsilon_{n}}{\varepsilon_{n}^{o}}, \frac{\varepsilon_{s}}{\varepsilon_{s}^{o}}, \frac{\varepsilon_{t}}{\varepsilon_{t}^{o}}\right\}=1
$$

The crack starts propogaating through mesh once the effective palstic strain more then or equal to the failure starin of the material

$$
\varepsilon_{e p} \geq \varepsilon_{f}
$$

\subsubsection{Quadratic Nominal Stress Criterion}

Damage is assumed to initiate when a quadratic interaction function involving the nominal stress ratios reaches a value of one. This criterion can be represented as

$$
\left\{\frac{\sigma_{n}}{\sigma_{n}^{o}}\right\}^{2}+\left\{\frac{\sigma_{s}}{\sigma_{s}^{o}}\right\}^{2}+\left\{\frac{\sigma_{t}}{\sigma_{t}^{o}}\right\}^{2}=1 .
$$

\subsubsection{Quadratic Nominal Strain Criterion}

Damage is to be initiated when a quadratic interaction function involving the nominal strain ratios reaches a value of one. This criterion can be represented as

$$
\left\{\frac{\varepsilon_{n}}{\varepsilon_{n}^{o}}\right\}^{2}+\left\{\frac{\varepsilon_{s}}{\varepsilon_{s}^{o}}\right\}^{2}+\left\{\frac{\varepsilon_{t}}{\varepsilon_{t}^{o}}\right\}^{2}=1,
$$

where $\sigma_{n}^{o}, \sigma_{s}^{o}$, and $\sigma_{t}^{o}$ represent the peak values of the nominal stress when the deformation is either purely normal to the interface or purely in the first or the second shear direction, respectively. In the same manner $\varepsilon_{n}^{o}, \varepsilon_{s}^{o}$, and $\varepsilon_{t}^{o}$ represent the peak values of the nominal strain when the deformation is either purely normal to the interface or in the first or the second shear direction respectively.

\subsection{Damage Evolution}

The damage evolution law describes the rate at which the material stiffness is degraded once the corresponding initiation criterion is reached. A scalar damage variable, $\mathrm{D}$, shows the overall damage in the material and captures the combined effects of all the active mechanisms. Initially it has a value of zero. If damage evolution is modeled, D monotonically evolves from 0 to 1 upon further loading 
after the initiation of damage. The stress components of the traction-separation model are affected by the damage according to

$$
\begin{aligned}
& \sigma_{n}=(1-D) \sigma_{n}^{c}, \\
& \sigma_{s}=(1-D) \sigma_{s}^{c}, \\
& \sigma_{t}=(1-D) \sigma_{t}^{c},
\end{aligned}
$$

where $\sigma_{n}^{c}, \sigma_{s}^{c}, \sigma_{t}^{c}$ are the stress component predicted by the elastic traction-separation behavior for the current strains without damage. Stress components $\sigma_{n}^{c}, \sigma_{s}^{c}, \sigma_{t}^{c} \geq 0$, otherwise no damage for compressive stiffness.

To mark out the evolution of damage under a combined effect of normal and shear deformation across the interface, an effective displacement defined as

$$
\delta_{e}=\sqrt{\delta_{n}^{2}+\delta_{s}^{2}+\delta_{t}^{2}}
$$

Damage variables (D) can be expressed as

$$
D=\frac{\delta_{f}\left(\delta_{m}^{\max }-\delta_{o}\right)}{\delta_{m}^{\max }\left(\delta_{f}-\delta_{o}\right)} .
$$

In the preceding expression and in all later references, $\delta_{m}^{\max }$ refers to the maximum value of the effective displacement attained during the loading history. Term $\delta_{f}-\delta_{o}$ is the effective displacement at complete failure, $\delta_{f}, \delta_{o}$ refer to displacement at complete damage, and start of damage respectively.

\subsection{Experimental Procedure}

An $\mathrm{Al}$ alloy specimen for different crack configurations are prepared for testing using $100 \mathrm{KN}$ servo hydraulic universal testing machine (UTM). Detailed experimental study are performed to assess the effect of changing the crack tip distance and crack offset distance on crack growth considering the multiple crack configurations. The one end of specimen was clamped in the UTM and load was applied monotonically from other side until final failure of the specimen (Fig. 4). The crack extension angle was measured from the fractured specimen and presented in the subsequent section 4 .

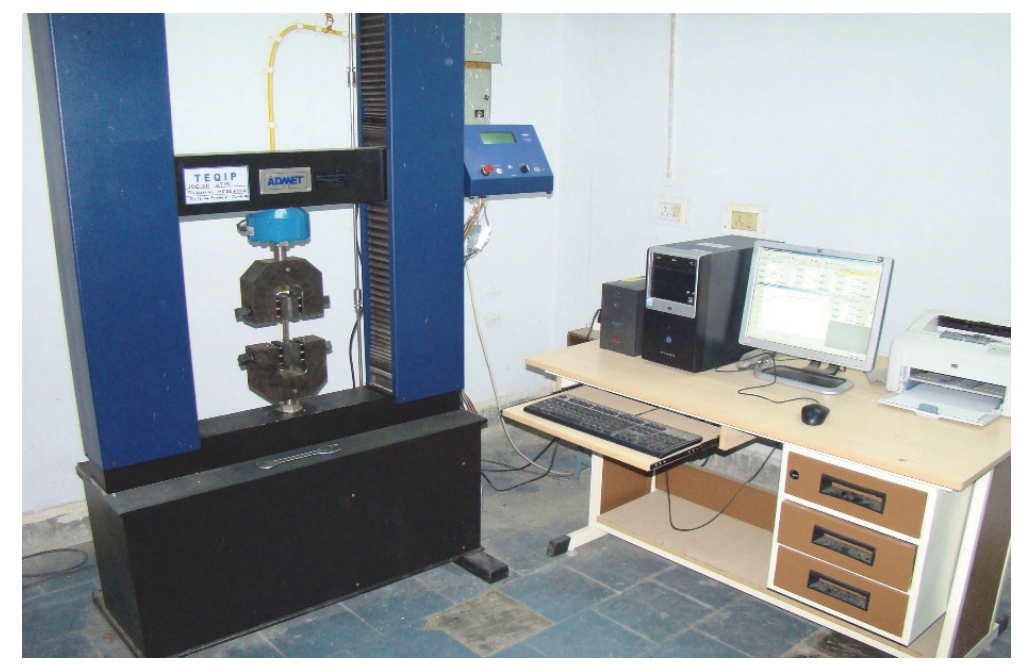

Fig. 4. Experimental setup for crack growth simulation

\subsection{FE Simulation of Crack Growth}


Specimen is divided in three region i.e. region-1, 2 and 3 (as shown in Fig. 5). Region -1 and 3 are for loading and application of boundary conditions whereas, region-2 is for the crack growth simulation. To capture the rapidly varying crack growth w.r.t. time refined mesh in the region around the crack tip is carried out. Analysis is carried out considering the elastic material properties for region one whereas elastic-plastic material properties is defined for region-2. Tensile loading on top edge of region-1 is applied gradually until the effective plastic strain reaches to failure stain of the material, and FE model is constrained on bottom edge of region-3. Effect of changing the parameters $\mathrm{S}$ and $\mathrm{H}$ on crack growth is studied under tensile loading condition. FE predicted crack growth direction is compared with the experimental results.

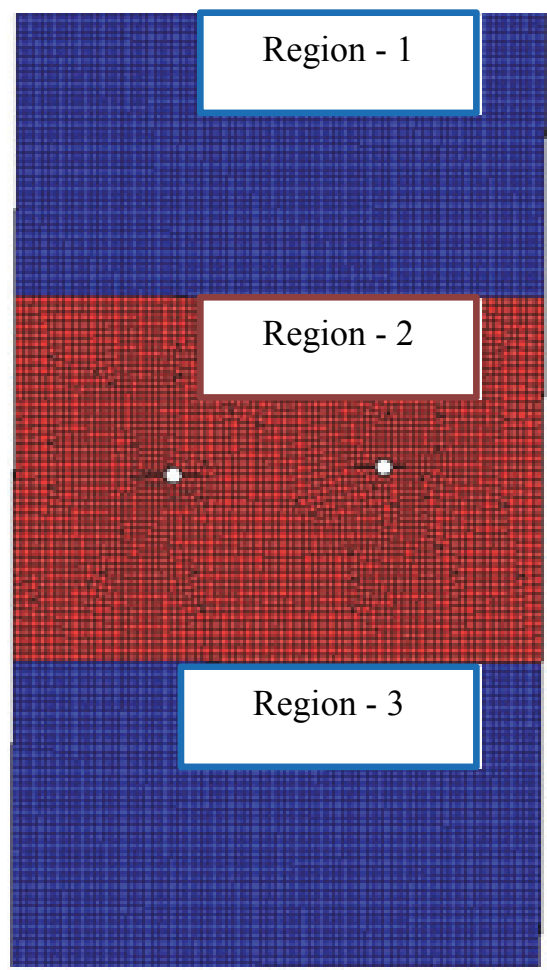

Fig. 5. Typical meshed model of cracked plate

\section{Validity of present FE analysis and discussion}

FE predicted crack growth direction shows good agreement with experimental results for all configurations of multiple cracks. Fig. 6 shows one of the typical simulation of multiple crack growth behavior for edge crack $\mathrm{S}=0, \mathrm{H}=10$. Two edge cracks (a) under tensile loading becomes in opening mode (b). Non-self-similar crack growths almost parallel to the loading axis were observed (c). Finally, the fracture of the specimen is shown (d). For all specimen at $S=0$, same behavior of crack growth is observed.

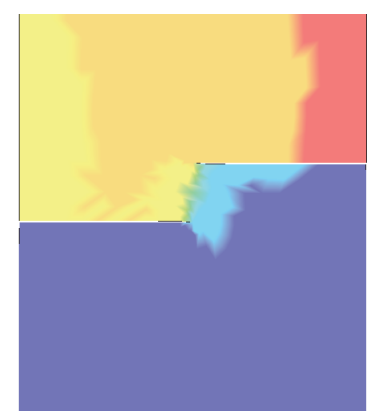

(a)

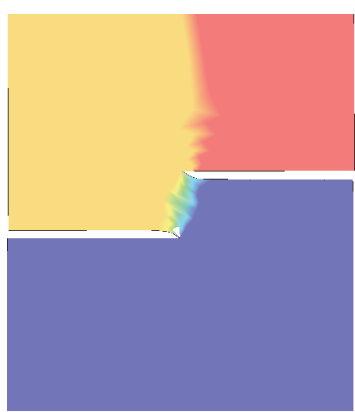

(b)

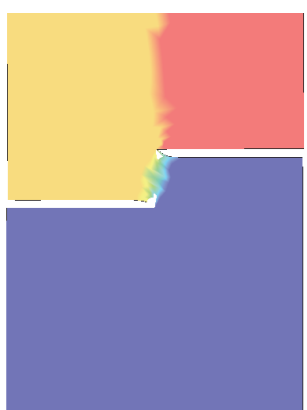

(c)

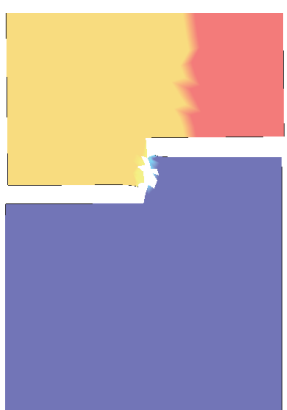

(d)

Fig. 6. Typical Crack growth for $\mathrm{S}=0, \mathrm{H}=10 \mathrm{~mm}$ :( a) Initial multiple edge cracks,(b) Opening mode, (c) Non-self-similar crack propagation, and (d) Fracture of the specimen 4.1. Examination of multiple offset edge cracks 
Fig. 7 (a) shows for $\mathrm{S}=0$, crack growth direction decreases with increase of $\mathrm{H}$. For all configuration of $\mathrm{S}=0$, crack moves almost perpendicular to the longitudinal axis. Non-self-similar crack growth is observed for all specimens at $S=0$. As crack tip distance became to zero, the position of both crack tips become perpendicular to each other, causing the coalescence of the cracks perpendicular to the longitudinal axis. Fig. 7 (b) shows the crack growth angle decreasing with increase of $\mathrm{S} / \mathrm{H}$. For $\mathrm{S} / \mathrm{H} \geq 4$, self-similar crack propagation is observed. The crack growth direction for stated specimen configuration is found less than $10^{\circ}$.

According to MTS criterion (Erdogan \& Sih 1963) the crack extension angle in terms of stress intensity factor is given as

$$
\theta=2 \tan ^{-1}\left[\frac{K_{1}}{4 K_{11}}+\sqrt{\left(\frac{K_{1}}{K_{11}}\right)^{2}+8}\right]
$$
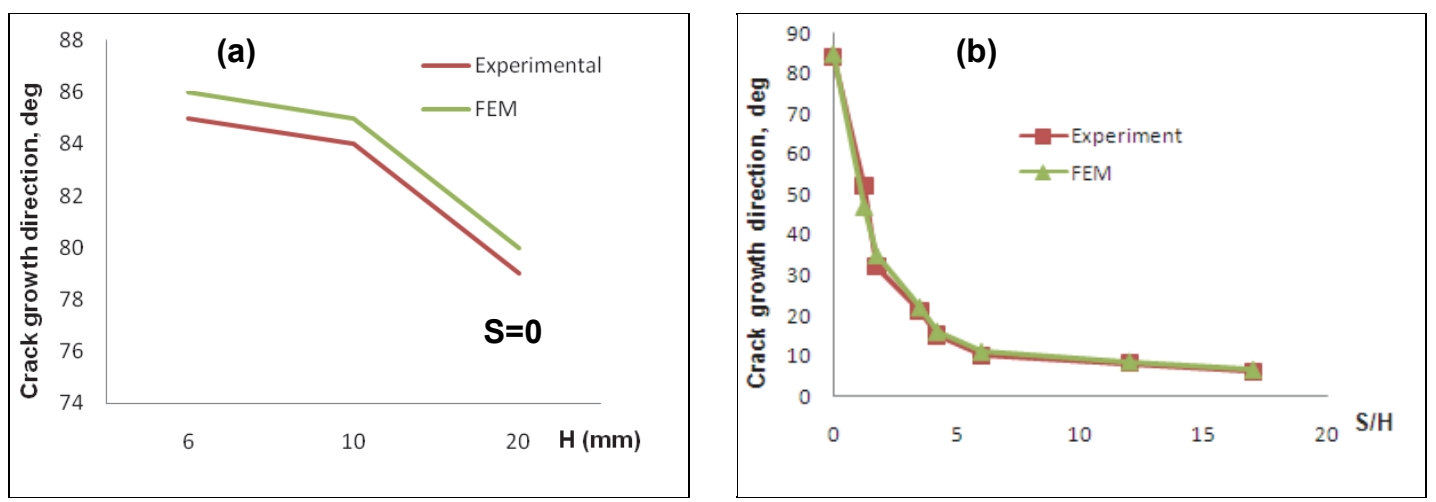

Fig. 7. Effect of crack tip distance and offset distance on crack growth of multiple edge cracks:(a)S=0,H=6 to $20 \mathrm{~mm}$, and (b) $\mathrm{S} / \mathrm{H}=0$ to 18

Using Eq. (9), the crack extension angle less than $10^{0}$ for $\mathrm{K}_{1} / \mathrm{K}_{\mathrm{II}}>10$. This indicates that crack propagate mainly under the influence of mode-I, and the effect of mode-II Stress intensity factor is about $1 / 10^{\text {th }}$ of mode-I. It can be concluded that for the present multiple crack configuration there is little effect of the presence of second crack as the crack moves almost perpendicular to loading axis. Whereas for $\mathrm{S} / \mathrm{H}<4$, non-self-similar crack propagation is observed indicates that cracks moves under the influence of mixed mode stress intensity factor, effect of mode-I stress intensity factor is reduced.

\subsection{Examination of multiple offset central cracks}

Figs. 8a-8c show the comparison of FE predicted crack growth with experimental results. The FE analysis results of predicted crack growth show good agreement with experimental results for all the configurations of cracks. Figs. (9a-9c) show the effect of changing crack tip distance and crack-offset distance on crack growth. Fig. 9(a) shows the crack growth direction is decreasing as crack tip distances increasing for constant value of crack offset distance. As crack tip distance increases for constant value of crack-offset distance, the diagonal angle between the cracks is decreasing. The crack coalescence is observed in smallest possible diagonal direction with increment of crack tip distance. Figs. 9b-9c show the crack growth direction is increasing as crack offset distance is increasing for constant value of crack tip distance. As the crack offset distance increases for constant value of crack tip distance, the diagonal angle between the crack tips is increasing, which causes the coalescence of crack with increase in crack growth angle. Fig. 9d shows the crack growth direction decreasing with increase of S/H. Self-similar crack growth is observed for $\mathrm{S} / \mathrm{H} \geq 3$ whereas non-self-similar crack is seen for $\mathrm{S} / \mathrm{H} \leq 3$.

(a) 


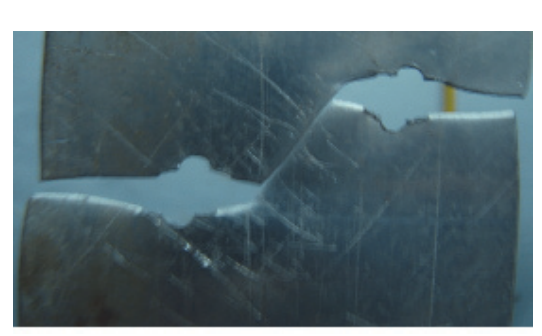

Testing

(c)

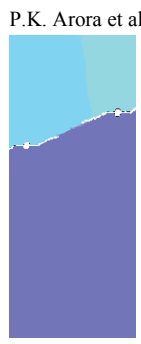

FEM

Testing

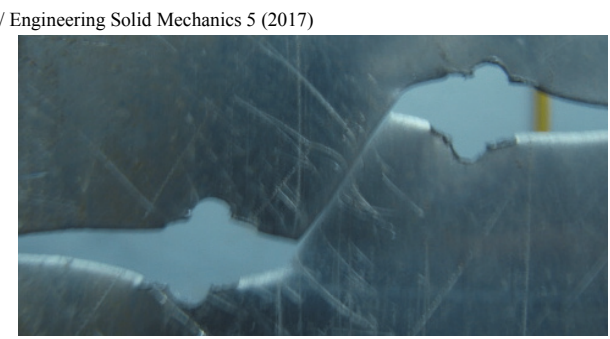

Testing

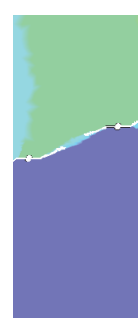

FEM

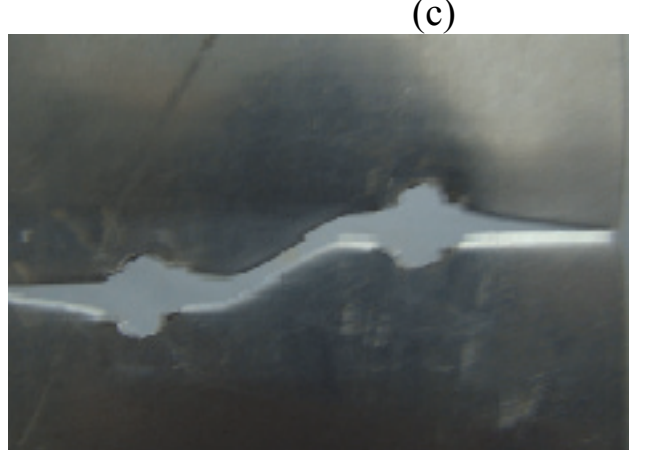

Fig. 8. Comparison of FE predicted crack growth w.r.t. experimental results: (a) $H=10 \mathrm{~mm}, \mathrm{~S}=20 \mathrm{~mm}$, (b) $\mathrm{H}=12.0 \mathrm{~mm}, \mathrm{~S}=20.0 \mathrm{~mm}$, and (c) $\mathrm{H}=6 \mathrm{~mm}, \mathrm{~S}=16 \mathrm{~mm}$
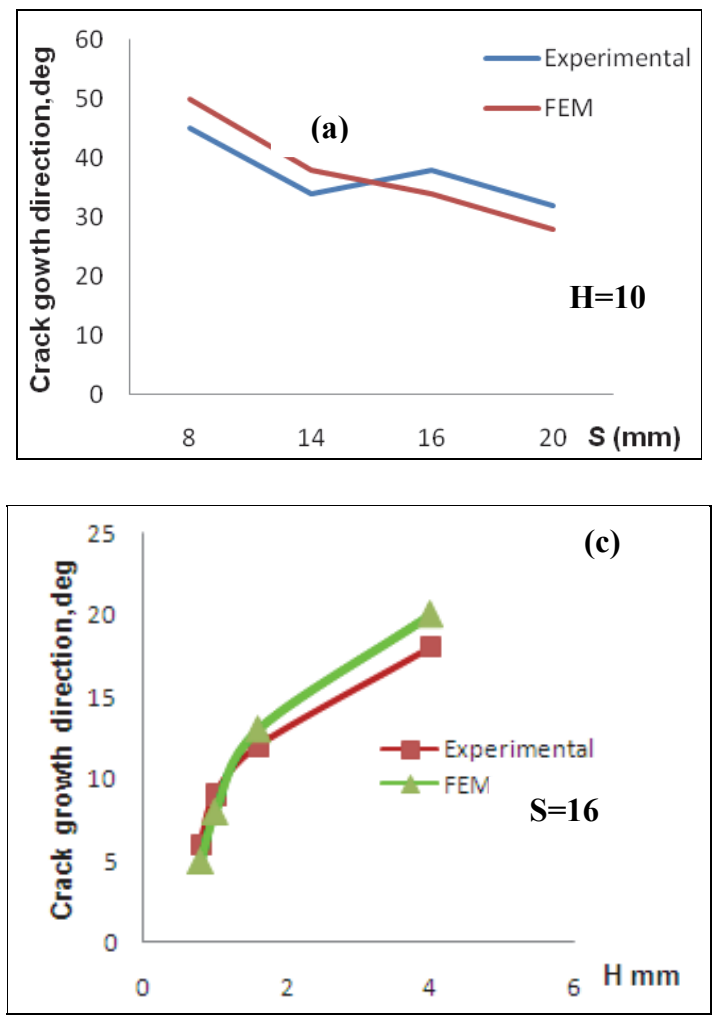
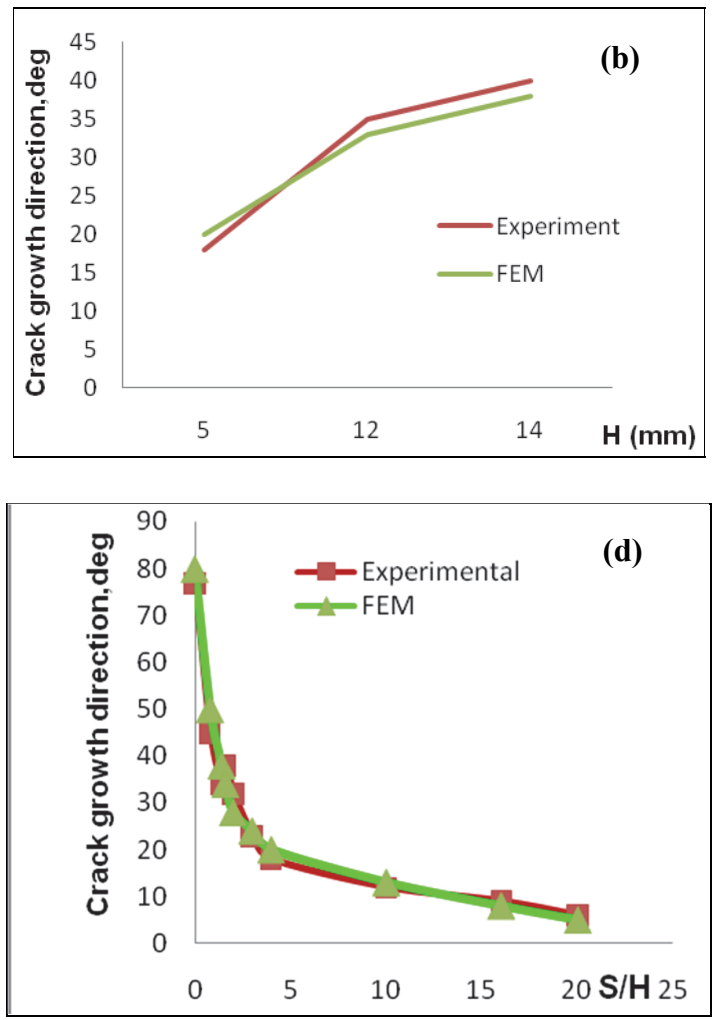

Fig. 9. Effect of crack tip distance $(\mathrm{S})$ and offset distance $(\mathrm{H})$ on crack growth direction for two central cracks :(a) $\mathrm{H}=10 \mathrm{~mm}, \mathrm{~S}=8$ to $20 \mathrm{~mm}$, (b) $\mathrm{S}=20 \mathrm{~mm}, \mathrm{H}=5$ to $14 \mathrm{~mm}$,(c) $\mathrm{S}=16 \mathrm{~mm}, \mathrm{H}=1$ to 4 $\mathrm{mm}$, and(d) $\mathrm{S} / \mathrm{H}=0$ to $20 \mathrm{~mm}$

\subsection{Examination of Multiple Central Inclined Cracks}

Figs. 10a-10d show the comparison of predicted crack growth for inclined crack at $\alpha=60^{\circ}$ based on FE analysis and test results. The FE predicted crack growth show good agreement with experimental results for all configurations of cracks.Figures 10a-10c show the effect of changing the crack tip distance (S) 
and crack-offset distance $(\mathrm{H})$ on crack growth. Fig 11a shows the crack growth direction is increasing as crack offset distance increasing for constant value of crack tip distance (S). Fig. 11b shows crack growth direction is decreasing as crack tip distance is increasing for constant value of H. Fig. 11c shows the crack growth direction decreasing with increase of $\mathrm{S} / \mathrm{H}$. Self- similar crack growth is observed for $\mathrm{S} / \mathrm{H} \geq 4$ whereas non-self -similar crack is seen for $\mathrm{S} / \mathrm{H} \leq 4$.

(a)

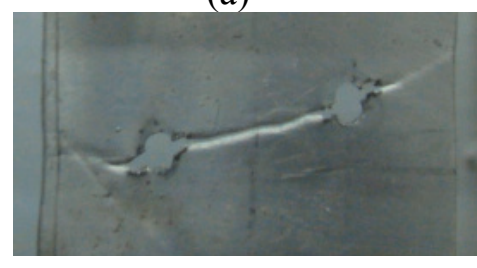

Testing

(c)

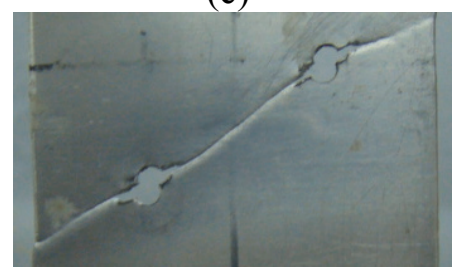

Testing

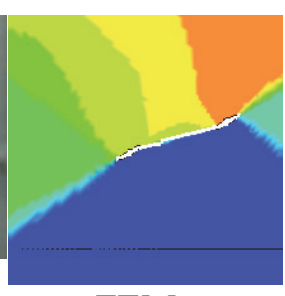

FEM

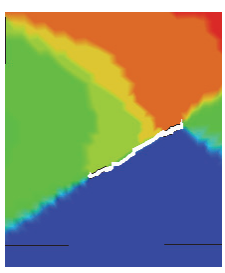

FEM (b)

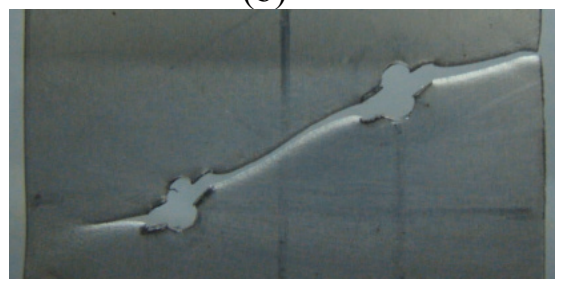

Testing

(d)

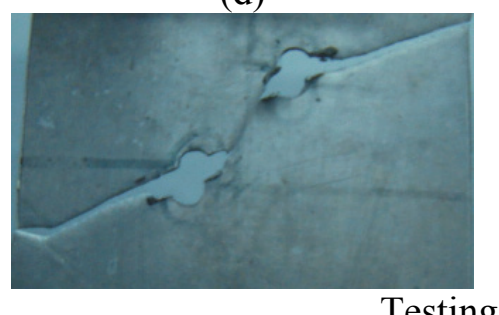

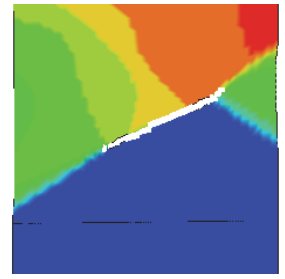

FEM

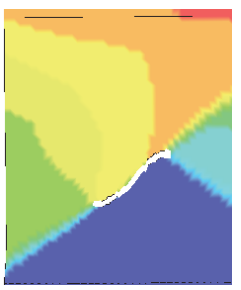

FEM

Fig. 10. Comparison of FE predicted crack growth w.r.t. experimental results (a) $\mathrm{H}=6.0 \mathrm{~mm}$ and $\mathrm{S}=$ $24.0 \mathrm{~mm}, \alpha=60^{0}$, (b) $\mathrm{H}=10.0 \mathrm{~mm}$ and $\mathrm{S}=24.0 \mathrm{~mm}, \alpha=60^{\circ}$ (c) $\mathrm{H}=14.0 \mathrm{~mm}$ and $\mathrm{S}=24.0 \mathrm{~mm}$, $\alpha=60^{0}$ (d) $\mathrm{H}=12 \mathrm{~mm}$ and $\mathrm{S}=11 \mathrm{~mm}, \alpha=60^{0}$

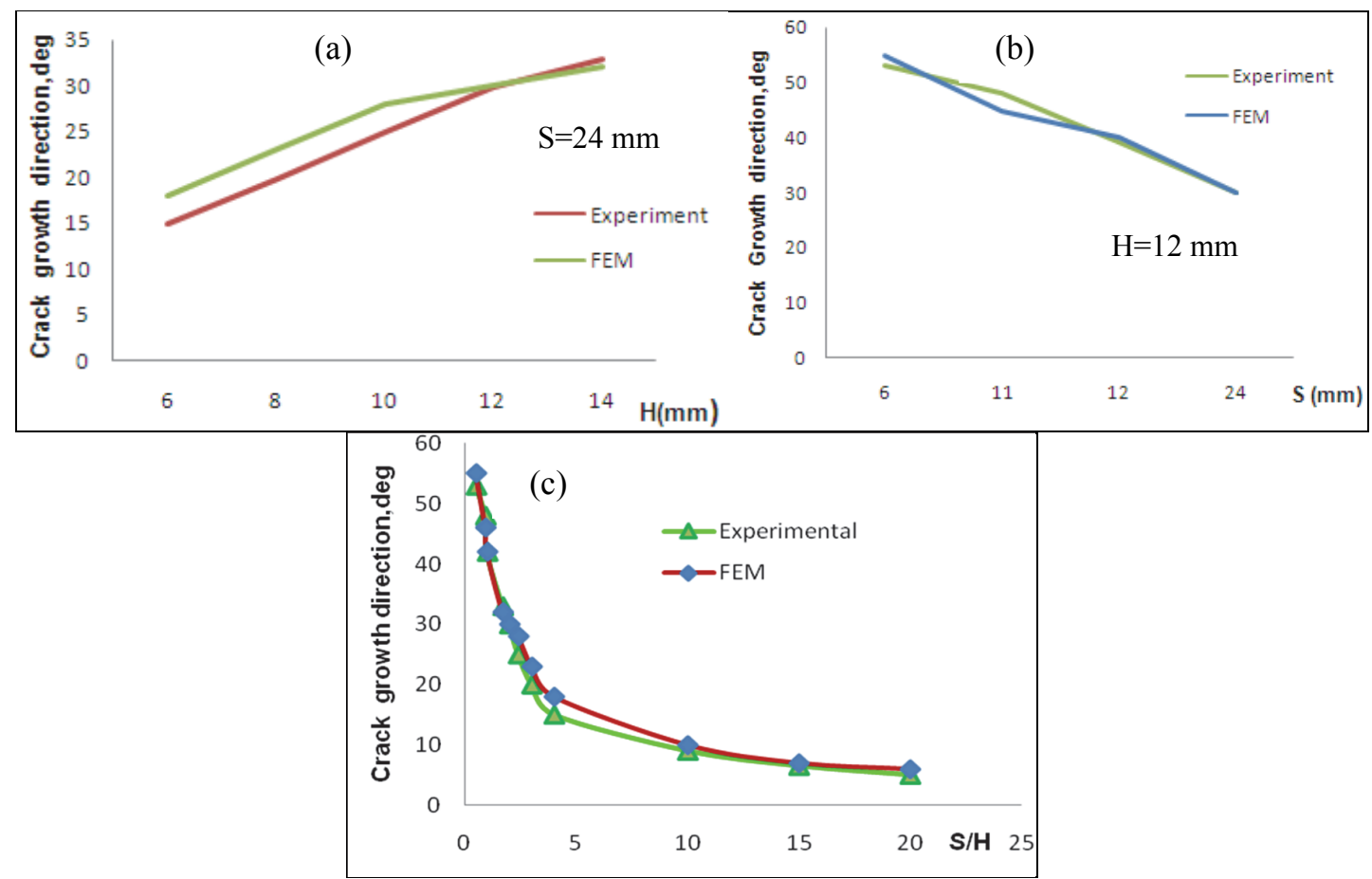

Fig. 11. Effect of crack tip distance $(\mathrm{S})$ and offset distance $(\mathrm{H})$ on crack growth direction for two inclined crack: (a) $\mathrm{S}=24 \mathrm{~mm}, \mathrm{H}=6$ to $14 \mathrm{~mm}$, (b) $\mathrm{H}=12 \mathrm{~mm}, \mathrm{~S}=6$ to $24 \mathrm{~mm}$, and (c) $\mathrm{S} / \mathrm{H}=0$ to $20 \mathrm{~mm}$ 


\section{Relation between $\theta, S$ and $H$}

Based on the analysis stated above, it can be concluded that crack growth direction is depend on the relative position of multiple crack. Further, mathematical equations based on the FE analysis and experimental results are introduced by isolating the curve in two segments i.e. for self-similar and non- self-similar crack propagation as follows:

\subsection{Multiple Edge Cracks}

Mathematical equations for multiple edge crack configuration are introduced based on FE analysis and experimental results by splitting the crack growth curve in two segments i.e. self-similar and non selfsimilar curve.

Condition I: Crack initiation angle in terms of $\mathrm{S} / \mathrm{H}$ for non self-similar crack growth can be evaluated as follows for $0<\mathrm{S} / \mathrm{H} \leq 4$, (Fig. 12a).

$$
\theta=-1.147(S / H)^{3}+11.45(S / H)^{2}-44.27(S / H)+85.19
$$

Condition II: Crack initiation angle in terms of $\mathrm{S} / \mathrm{H}$ for self-similar crack growth can be expressed as follows for $\mathrm{S} / \mathrm{H} \geq 4$ (Fig. 12b).

$$
\theta=-0.006(S / H)^{2}-0.224(S / H)+11.56
$$

The regression Eqs. (10-11) are quite consistent with FE and experimental results with correlation coefficient, $r^{2} \geq 0.98$.
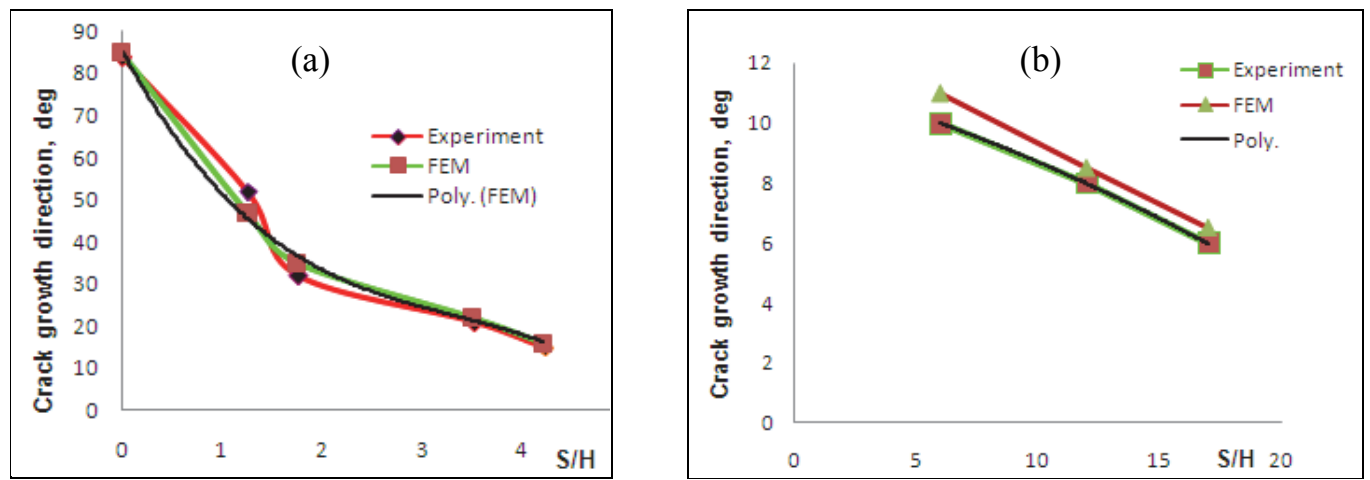

Fig. 12. Representation of polynomial equations for multiple edge cracks configurations based on FEM and test results: (a) $\mathrm{S} / \mathrm{H}=0$ to $4 \mathrm{~mm}$, and (b) $\mathrm{S} / \mathrm{H}=5$ to $18 \mathrm{~mm}$

\subsection{Multiple Central Cracks}

Mathematical equations for multiple central crack configurations are introduced based on FE analysis and experimental results for self-similar and non self-similar crack propagation (Fig.13).

Condition 1: Crack initiation angle in terms of $\mathrm{S} / \mathrm{H}$ for non self-similar crack growth can be expressed as follows for $0<\mathrm{S} / \mathrm{H} \leq 3$ (Fig. 13a).

$$
\theta=7.351(S / H)^{2}-40.44(S / H)+79.40
$$

Condition II: Crack initiation angle in terms of $\mathrm{S} / \mathrm{H}$ for self-similar crack growth can be expressed as follows for $\mathrm{S} / \mathrm{H} \geq 3$ (Fig. 13b).

$\theta=0.036(S / H)^{2}-1.876(S / H)+28.18$ 
The regression Eqs. (12-13) are quite consistent with FE and experimental results with correlation coefficient, $r^{2} \geq 0.98$.
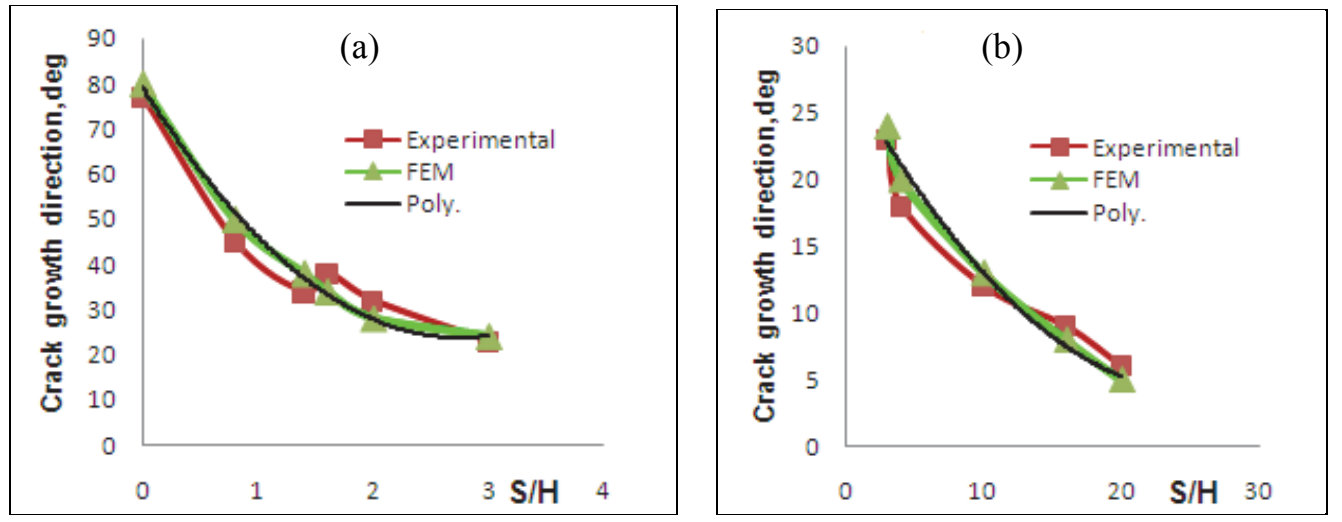

Fig. 13. Representation of polynomial equations for multiple central cracks based on FEM and test results: (a) $\mathrm{S} / \mathrm{H}=0$ to $3 \mathrm{~mm}$ and (b) $\mathrm{S} / \mathrm{H}=3$ to $20 \mathrm{~mm}$

\subsection{Multiple Inclined Cracks}

Mathematical equations for multiple inclined crack configurations are introduced based on $\mathrm{FE}$ analysis and experimental results for self-similar and non self- similar crack propagation (Fig.14).

Condition 1: Crack initiation angle in terms of $\mathrm{S} / \mathrm{H}$ for non self-similar crack growth can be evaluated as follows for $0<\mathrm{S} / \mathrm{H} \leq 4$, (Fig. 14a).

$$
\theta=2.769(S / H)^{2}-22.30(S / H)+63.75
$$

Condition II: Crack initiation angle in terms of $\mathrm{S} / \mathrm{H}$ for self-similar crack growth can be evaluated as follows for $\mathrm{S} / \mathrm{H} \geq 4$, (Fig 14b).

$$
\theta=0.034(S / H)^{2}-1.434(S / H)+20.13
$$

The regression Eq. (14-15) are quite consistent with FEM and experimental data with correlation coefficients, $r^{2} \geq 0.98$.
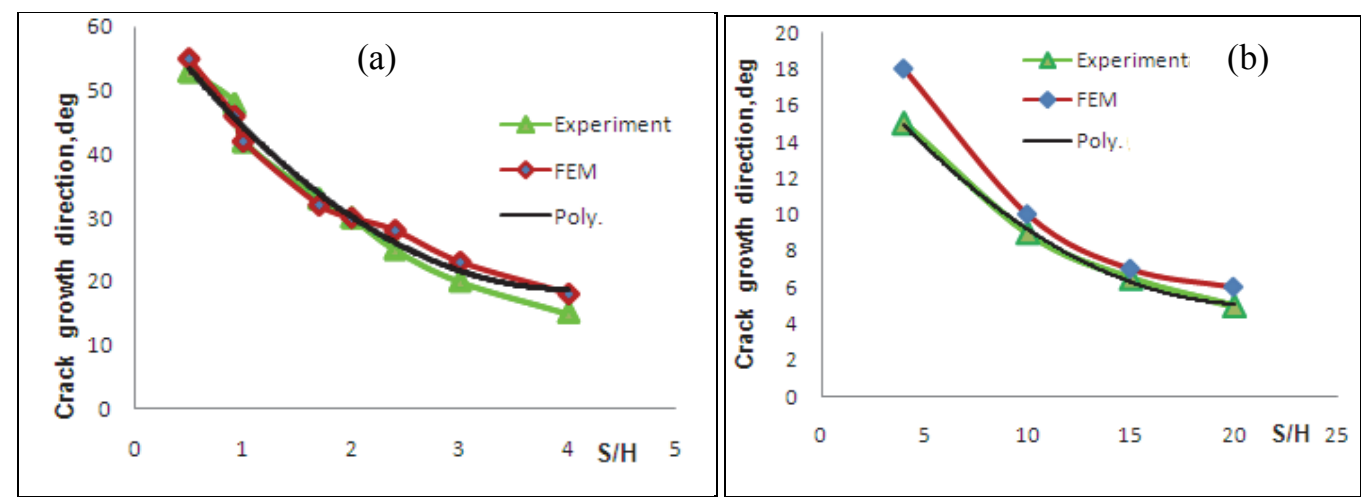

Fig.14. Representation of polynomial equations for multiple inclined cracks based on FEM and test results: (a) $\mathrm{S} / \mathrm{H}=0$ to $4 \mathrm{~mm}$ and (b) $\mathrm{S} / \mathrm{H}=4$ to $20 \mathrm{~mm}$.

\section{Conclusions}


The paper presents the effect of changing the crack tip and offset distances on crack growth using FE and experimental approach. An approximated crack growth propagation and coalescence of multiple cracks under tensile loading were simulated and compared with experimental results. Mathematical model for self-similar and non-self similar crack growth are derived for different configurations of edge cracks. The following conclusions can be drawn based on present study.

I. FE prediction of crack growth direction shows good agreement with experimental results.

II. Crack growth of multiple cracks are depend on their relative position of crack defined by crack tip distance, crack offset distance.

III. As crack offset distances increase, non-self similar crack propagation is observed for constant value of crack tip distance vice versa self-similar crack propagation is seen as crack tip distance increases for constant value of crack-offset distance.

IV. Self-similar crack propagation is observed for $\mathrm{S} / \mathrm{H} \geq 4$, indicates presence of second crack is not much influencing the propagation of first crack. Crack progresses under the influence of mode-I SIF.

V. Non self-similar crack propagation is observed for $\mathrm{S} / \mathrm{H}<4$, indicates the presence of second crack is influencing the propagation of first crack. The crack progresses under the influence of mixed mode SIF.

VI. As the crack tip distance became to zero, crack propagation is almost parallel to the loading axis, shows that the propagation is under the influence of mode- II SIF.

VII. Crack coalescence is observed in the smallest possible diagonal direction of crack tips. As the crack offset distance increases for constant value of crack tip distance, the diagonal angle between the crack tips is increasing, which causes the coalescence of crack with increase in crack growth angle. Vice- versa with increment of crack tip distance for constant value of crack-offset distance, the diagonal angle between the crack tips is decreasing causing the propagation of cracks with decrease in crack growth angle.

\section{References}

ABAQUS, C. A. E. (2011). User's manual. Abaqus analysis user's manual.

Akbardoost, J., Ayatollahi, M. R., Aliha, M. R. M., Pavier, M. J., \& Smith, D. J. (2014). Size-dependent fracture behavior of Guiting limestone under mixed mode loading. International Journal of Rock Mechanics and Mining Sciences, 71, 369-380.

Aliha, M. R. M., Bahmani, A., \& Akhondi, S. (2016a). Mixed mode fracture toughness testing of PMMA with different three-point bend type specimens. European Journal of Mechanics-A/Solids, 58, 148-162.

Aliha, M. R. M., Berto, F., Bahmani, A., Akhondi, S., \& Barnoush, A. (2016b). Fracture assessment of polymethyl methacrylate using sharp notched disc bend specimens under mixed mode I+ III loading. Physical Mesomechanics, 19(4), 355-364.

Aliha, M. R. M., \& Ayatollahi, M. R. (2008). On mixed-mode I/II crack growth in dental resin materials. Scripta Materialia, 59(2), 258-261.

Ayatollahi, M. R., Aliha, M. R. M., \& Hassani, M. M. (2006). Mixed mode brittle fracture in PMMAan experimental study using SCB specimens. Materials Science and Engineering: A, 417(1), 348356.

Ayatollahi, M. R., Aliha, M. R. M., \& Saghafi, H. (2011). An improved semi-circular bend specimen for investigating mixed mode brittle fracture. Engineering Fracture Mechanics, 78(1), 110-123.

Bombardier, Y., \& Liao, M. (2011). Stress intensity factor solution for cracks at an offset loaded fastener hole. Journal of Aircraft, 48(3), 910-918.

Cadini, F., Zio, E., \& Avram, D. (2009). Monte Carlo-based filtering for fatigue crack growth estimation. Probabilistic Engineering Mechanics, 24(3), 367-373.

Cisilino, A. P., \& Aliabadi, M. H. (1997). Three-dimensional BEM analysis for fatigue crack growth in welded components. International Journal of Pressure Vessels and Piping, 70(2), 135-144.

De Morais, A. B. (2007). Calculation of stress intensity factors by the force method. Engineering Fracture Mechanics, 74(5), 739-750. 
Erdogan, F., \& Sih, G. C. (1963). On the crack extension in plates under plane loading and transverse shear. Journal of Basic Engineering, 85(4), 519-527.

Kamaya, M., \& Totsuka, N. (2002). Influence of interaction between multiple cracks on stress corrosion crack propagation. Corrosion Science, 44(10), 2333-2352.

Kamaya, M. (2008). Growth evaluation of multiple interacting surface cracks. Part I: Experiments and simulation of coalesced crack. Engineering Fracture Mechanics, 75(6), 1336-1349.

Lacarac, V. D., Garcia-Granada, A. A., Smith, D. J., \& Pavier, M. J. (2004). Prediction of the growth rate for fatigue cracks emanating from cold expanded holes. International Journal of Fatigue, 26(6), 585-595.

Lee, H., \& Jeon, S. (2011). An experimental and numerical study of fracture coalescence in pre-cracked specimens under uniaxial compression. International Journal of Solids and Structures, 48(6), 979999.

Liu, P. F., Hou, S. J., Chu, J. K., Hu, X. Y., Zhou, C. L., Liu, Y. L., ... \& Yan, L. (2011). Finite element analysis of postbuckling and delamination of composite laminates using virtual crack closure technique. Composite Structures, 93(6), 1549-1560.

Li, H., \& Chandra, N. (2003). Analysis of crack growth and crack-tip plasticity in ductile materials using cohesive zone models. International Journal of Plasticity, 19(6), 849-882.

Mahanty, D. K., \& Maiti, S. K. (1990). Experimental and finite element studies on mode I and mixed mode (I and II) stable crack growth-I. Experimental. Engineering Fracture Mechanics, 37(6), 1237-1250.

Mirsayar, M. M., Berto, F., Aliha, M. R. M., \& Park, P. (2016). Strain-based criteria for mixed-mode fracture of polycrystalline graphite. Engineering Fracture Mechanics, 156, 114-123.

Romlay, F. R. M., Ouyang, H., Ariffin, A. K., \& Mohamed, N. A. N. (2010). Modeling of fatigue crack propagation using dual boundary element method and Gaussian Monte Carlo method. Engineering Analysis with Boundary Elements, 34(3), 297-305.

Sih, G. C. (1974). Discussion:'Some observations on Sih's strain energy density approach for fracture prediction', by I. Finnie and HO Weiss. International Journal of Fracture, 10(2), 279-283.

Sih, G. C., \& Barthelemy, B. M. (1980). Mixed mode fatigue crack growth predictions. Engineering Fracture Mechanics, 13(3), 439-451.

Yan, X. (2006). Multiple crack fatigue growth modeling by displacement discontinuity method with crack-tip elements. Applied Mathematical Modelling, 30(6), 489-508.

Xie, D., \& Biggers, S. B. (2006). Progressive crack growth analysis using interface element based on the virtual crack closure technique. Finite Elements in Analysis and Design, 42(11), 977-984.

Wang, Q., \& Zhang, X. (1999). A closed form solution about stress intensity factors of shear modes for 3-D finite bodies with eccentric cracks by the energy release rate method. International Journal of Solids and Structures, 36(7), 971-998.

Wessel, C., Cisilino, A., Santi, O., Otegui, J., \& Chapetti, M. (2001). Numerical and experimental determination of three-dimensional multiple crack growth in fatigue. Theoretical and Applied Fracture Mechanics, 35(1), 47-58.

Xiaofeng, X., Yunwen, F., Zhongwei, Y., \& Yuansheng, F. (2009). Research on the plane multiple cracks stress intensity factors based on stochastic finite element method. Chinese Journal of Aeronautics, 22(3), 257-261.

Zhao, J., Xie, L., Liu, J., \& Zhao, Q. (2012). A method for stress intensity factor calculation of infinite plate containing multiple hole-edge cracks. International Journal of Fatigue, 35(1), 2-9.

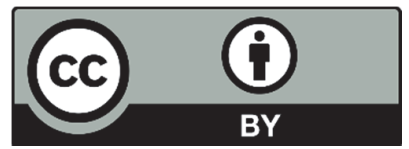

(C) 2017 by the authors; licensee Growing Science, Canada. This is an open access article distributed under the terms and conditions of the Creative Commons Attribution (CC-BY) license (http://creativecommons.org/licenses/by/4.0/). 